\title{
Bugs, TNF- $\alpha$ and IBD: More fuel for the fire
}

\author{
Gordon R Greenberg MD
}

\begin{abstract}
ARTICLES
Zareie M, Singh PK, Irvine EJ, Sherman PM, McKay DM, Perdue MH. Monocytes/macrophage activation by normal bacteria and bacterial products. Implications for altered epithelial function in Crohn's disease. American Journal of Pathology 2001;158:1101-1109

Chang Q, Tepperman BL. The role of protein kinase C isozymes in TNF- $\alpha$-induced cytotoxicity to a rat intestinal epithelial cell line. American Journal of Physiology. Gastrointestinal and Liver Physiology 2001;280:G572-G583.
\end{abstract}

A $\mathrm{n}$ inappropriate immune response mediated by commensal flora may contribute to the pathogenesis of inflammatory bowel disease. Zareie et al sought to determine whether a nonpathogenic bacteria (Escherichia coli) or lipopolysaccharide (LPS), a bacterial product, alters epithelial cell function in the presence of monocytes/macrophages. Lamina propria mononuclear cells (LPMCs) and peripheral blood monocytes (PBMs) were obtained from patients with Crohn's disease and control patients. T84 epithelial cell monolayers were cocultured with nonactivated or LPS-activated LPMCs or PBMs. LPS-activated PBMs from control subjects and patients with Crohn's dis- ease increased the baseline short-circuit current $\left(\mathrm{I}_{\mathrm{SC}}\right)$ by approximately $300 \%$ and reduced the transepithelial electrical resistance by approximately $40 \%$. Coculture with control LPMCs did not alter epithelial cell function, whereas LPMCs from patients with Crohn's disease spontaneously secreted tumour necrosis factor-alpha (TNF- $\alpha$ ) and induced epithelial changes similar to those caused by LPSactivated PBMs. Coculture with E coli and PBMs produced similar changes in epithelial cell function that were abrogated by an anti-TNF antibody. Thus, LPMCs of patients with Crohn's disease are spontaneously activated, perhaps by lumenal bacteria, and cause significant direct alterations in epithelial ion transport and barrier function.

TNF- $\alpha$ plays a central role in mediating the inflammatory response associated with Crohn's disease. The intracellular signalling mediators of the actions of TNF- $\alpha$ may include protein kinase $\mathrm{C}$ ( $\mathrm{PKC})$. Chang and Tepperman investigated the role of $\mathrm{PKC}$ isoforms in the mediation of two of the actions of TNF- $\alpha$ - cytotoxicity and apoptosis using the rat epithelial cell line IEC-18. Cell damage was increased by exogenous TNF- $\alpha$, and this effect was increased with the addition of actinomycin $\mathrm{D}$, suggesting that new protein synthesis contributes to this cytotoxic effect of TNF- $\alpha$. TNF- $\alpha$ also induced the translocation of PKC- $\alpha,-\delta$ and $-\varepsilon$ from the cytosol to membranes, and both the cytotoxic and apoptotic effects of TNF- $\alpha$ were decreased by pretreatment with a PKC- $\varepsilon$ translocation inhibitor. Capase-3, an enzyme implicated in the mediation

Mt. Sinai Hospital, University of Toronto, Toronto, Ontario

Correspondence and reprints: Dr Gordon R Greenberg, Mt Sinai Hospital, 600 University Avenue, Toronto, Ontario M5G 1 X5.

Telephone 416-586-4727, fax 416-586-4802 
of apoptosis, was activated by TNF- $\alpha$, and this effect was abrogated by inhibition of PKC- $\varepsilon$ and $-\delta$ with a reduction of apoptosis. Thus, activation of selective PKC isoforms mediates the effects of TNF- $\alpha$ on cell injury and apoptosis.

\section{COMMENT}

Although the pathogenesis of Crohn's disease is unknown, investigations in animals and humans support the notion that an exaggerated immune response to enteric commensal flora or their bacterial products plays an important role. The intestinal inflammation of Crohn's disease is associated with a distinct population of hyperreactive monocyte-like macrophages recruited from the periphery to the intestinal mucosa that, in turn, release various cytokines including TNF- $\alpha$. Zareie et al have clarified the role of commensal flora in macrophage activation and the associated effects on epithelial cell function. Only LPMCs isolated from patients with Crohn's disease showed spontaneous and LPS-stimulated TNF- $\alpha$ secretion, adding to previous observations (1) that tolerance to enteric flora or their products is lost in patients with IBD. The effects of TNF- $\alpha$ included a reduced response to forskolin, indicating that TNF- $\alpha$ causes distinct alterations in epithelial function, including effects on calcium- and cAMP-mediated chloride transport. Moreover, similar changes in TNF- $\alpha$ and epithelial cell function occurred after co-incubation with a nonpathogenic strain of E coli, emphasizing that normal commensal flora can alter intestinal epithelial cell function and that TNF- $\alpha$ is a central player. In addition to effects on cellular integrity, TNF- $\alpha$ also plays a central role in apoptosis through activation of the death domain of the TNF receptor I (2). Certain actions of TNF- $\alpha$ may be mediated by PKC, one of the key intracellular signalling mediators, and several isoenzymes of PKC have been identified that individually cause selective regulation of numerous intestinal functions, including cell growth, differentiation and apoptosis. Chang and Tepperman have provided evidence that $\mathrm{PKC}$ is an important mediator of the actions of TNF- $\alpha$ on intestinal epithelial cells and that it does so through distinct isoforms. Thus, the $\mathrm{PKC}-\delta$ isoform predominately mediates cell injury, whereas PKC- $\varepsilon$ contributes to apoptosis. Moreover, the initiation and execution of apoptosis includes an essential role for capases, a family of cysteine proteases. Chang and Tepperman have also identified a key role for capase-3 activation in TNF- $\alpha$-induced apoptosis. Interestingly, however, this effect was augmented by actinomycin $\mathrm{D}$, suggesting that TNF- $\alpha$-mediated increases in capase- 3 are under regulation of an unidentified inhibitory protein. These investigations contribute to the understanding of intracellular mechanisms regulating TNF- $\alpha$ actions and are important because LPMCs in patients with Crohn's disease are resistant to apoptosis. Moreover, recent evidence (3) indicates that one of the mechanisms whereby infliximab achieves a beneficial effect is via apoptosis of circulating monocytes through activation of capase- 8 . Together, the two studies reviewed here provide further understanding of the mechanisms whereby TNF- $\alpha$ production is increased and of the signals by which TNF- $\alpha$ cause cellular injury and apoptosis. Such information could have important implications in the development of new strategies for the therapy of patients with inflammatory bowel disease.

\section{REFERENCE}

1. Duchmann R, Kaiser I, Hermann E, Mayet W, Ewe K, Meyer zum Buschenfelde KH. Tolerance exists towards resident intestinal flora but is broken in active inflammatory bowel disease (IBD). Clin Exp Immunol 1995;102:448-55.

2. Ashkenazi A, Dixit VM. Death receptors: signaling and modulation. Science 1998;281:1305-8.

3. Lugering A, Schmidt M, Lugering N, Pauels HG, Domschke W, Kucharzik T. Infliximab induces apoptosis in monocytes from patients with chronic active Crohn's disease by using a caspase-dependent pathway. Gastroenterology 2001;121:1145-57 


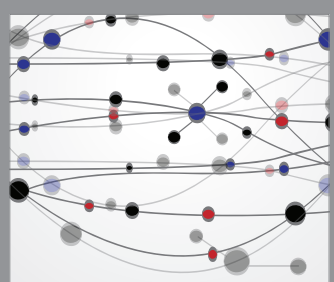

The Scientific World Journal
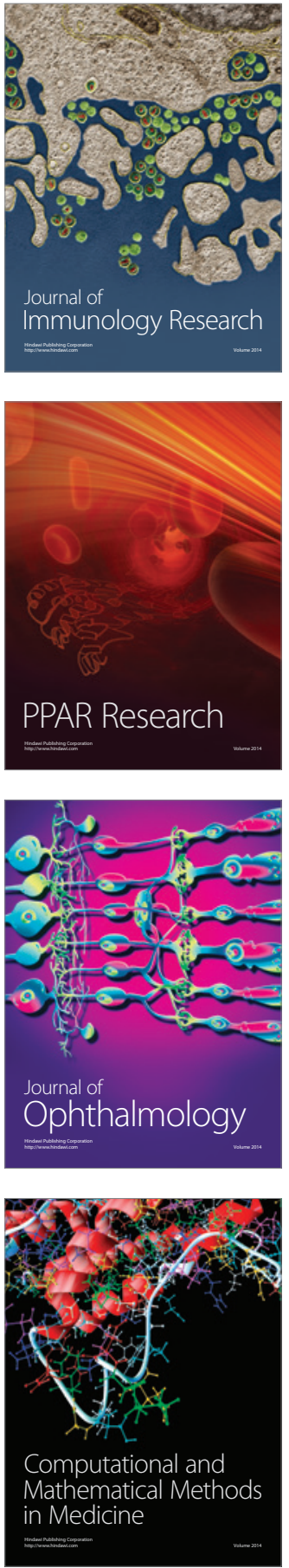

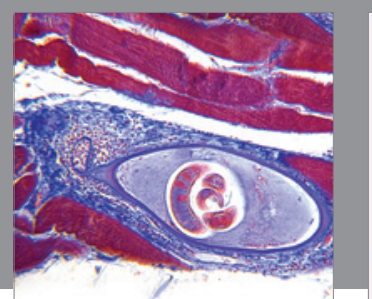

Gastroenterology Research and Practice

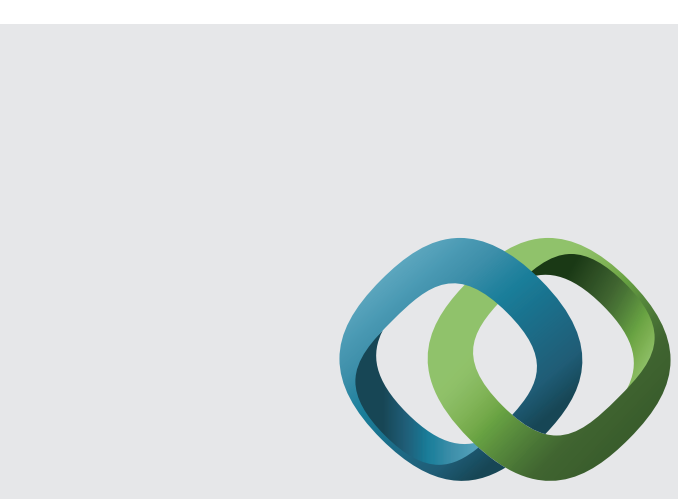

\section{Hindawi}

Submit your manuscripts at

http://www.hindawi.com
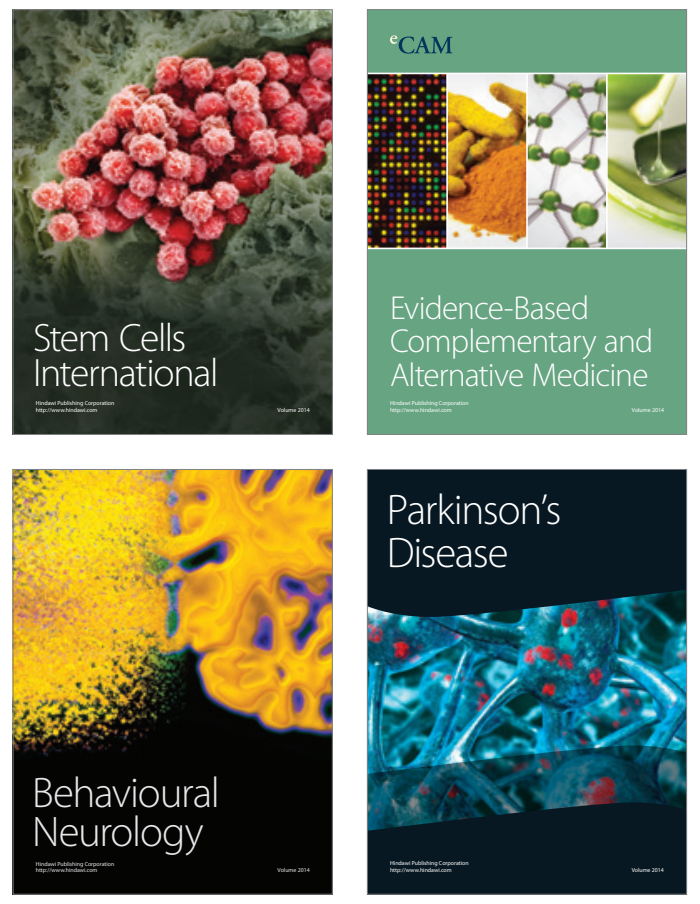
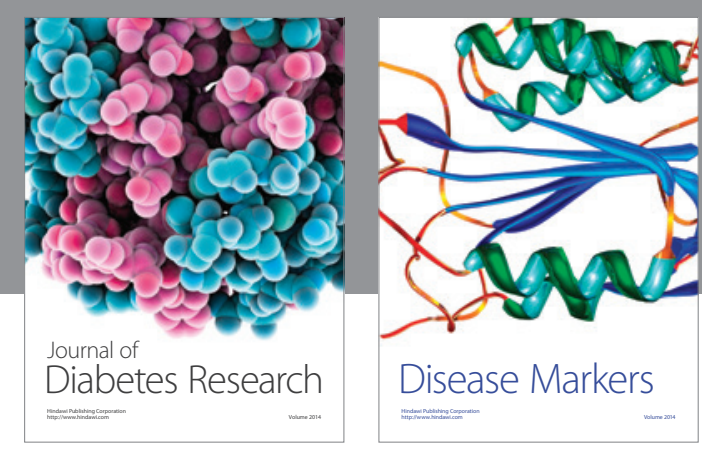

Disease Markers
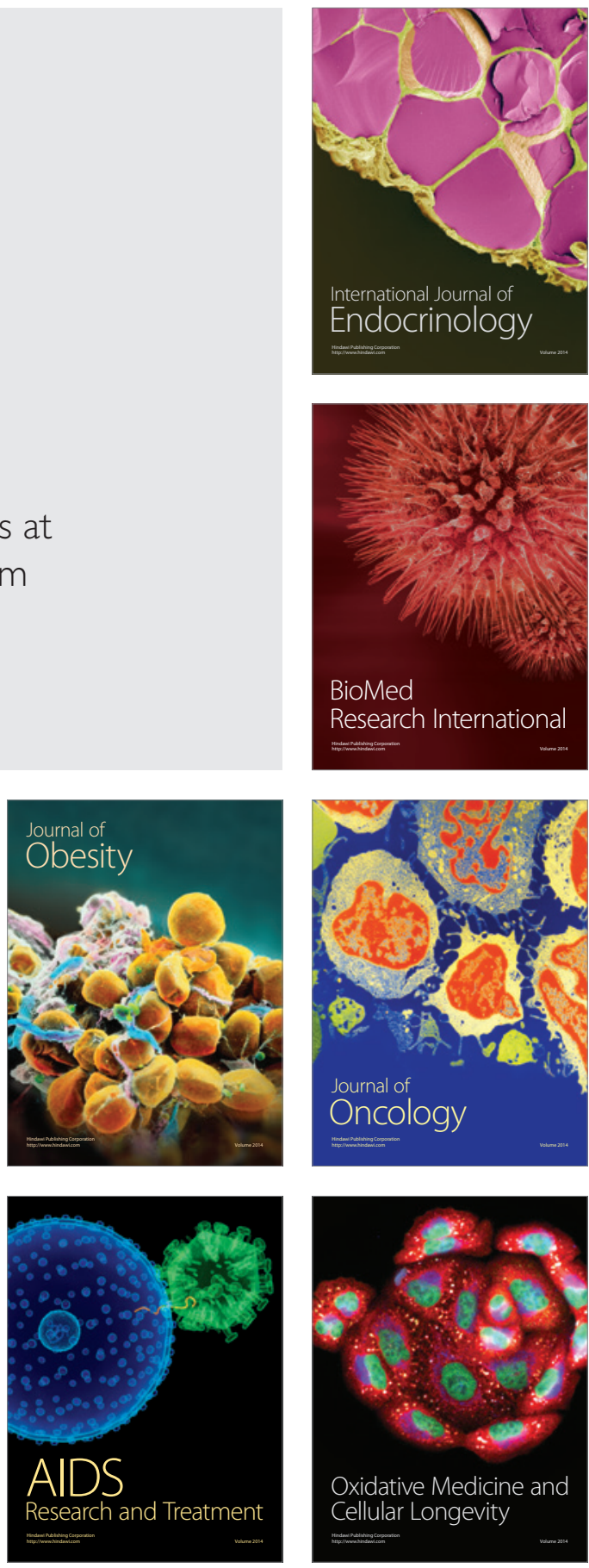